\title{
DHEA Lessens Depressive-Like Behavior via GABA-ergic Modulation of the Mesolimbic System
}

\author{
Rotem Genud', Avia Merenlender', Iris Gispan-Herman', Rachel Maayan', Abraham Weizman ${ }^{2,3}$ and \\ Gal Yadid*, I \\ 'The Mina \& Everard Goodman Faculty of Life Sciences and The Leslie and Susan Gonda (Goldschmied) Multidisciplinary Brain Research Center, \\ Bar-Ilan University, Ramat-Gan, Israel; ${ }^{B}$ Biological Psychiatry, Felsenstein Medical Research Center, Beilinson Campus, Petah-Tikva, Israel; ${ }^{3}$ Sackler \\ Faculty of Medicine, Tel-Aviv University, Tel-Aviv, Israel
}

\begin{abstract}
Alterations in the levels of dehydroepiandrosterone (DHEA) in the brain can allosterically modulate $\gamma$-aminobutyric-acid-type-A $\left(G_{A B A} R\right), N$-methyl-D-aspartate (NMDAR), and Sigma-I $(\sigma \mid R)$ receptors. In humans, DHEA has antidepressive effects; however, the mechanism is unknown. We examined whether alterations in DHEA also occur in an animal model of depression, the Flinders-sensitiveline (FSL) rats, with the intention of determining the brain site of DHEA action and its antidepressant mechanism. We discovered that DHEA levels were lower in some brain regions involved with depression of FSL rats compared to Sprague-Dawley (SD) controls. Moreover, DHEA ( I mg/kg IP for I 4 days)-treated FSL rats were more mobile in the forced swim test than FSL controls. In the NAc and VTA, significant changes were observed in the levels of the $\delta$-subunit of GABA, but not of $\sigma \mid R$ mRNA, in FSL rats compared to SD rats. The $\delta$-subunit controls the sensitivity of the $G_{A B A} R$ to the neurosteroid. Indeed, treatment ( 14 days) of FSL rats with the GABA agonist muscimol $(0.5 \mathrm{mg} / \mathrm{kg}$ ), together with DHEA (a negative modulator of GABA $\mathrm{A}$ ), reversed the effect of DHEA on immobility in the swim test. Perfusion of DHEA sulfate (DHEAS) ( $3 \mathrm{nM}$ and $30 \mathrm{nM}$ for 14 days) into the VTA and NAc of FSL rats improved their performance in the swim test for at least 3 weeks post-treatment. Our results imply that alterations in DHEA are involved in the pathophysiology of depression and that the antidepressant action of DHEA is mediated via GABA $\mathrm{A}_{\mathrm{Rs}}$ in the NAc and VTA. Neuropsychopharmacology (2009) 34, 577-584; doi: I0.1038/npp.2008.46; published online 2I May 2008
\end{abstract}

Keywords: depression; dehydroepiandrosterone; Flinders sensitive line rats; GABA-ergic; mesolimbic; neurotransmitter receptors

\section{INTRODUCTION}

Depressive disorders are serious illnesses and a public health problem. Major depression, which usually develops early in life and can last a lifetime, impairs the overall occupational and social functioning, thus affecting a patient's quality of life (Angst, 1992). Most antidepressants improve monoaminergic neurotransmission directly or indirectly, and although their pharmacological action is immediate, their therapeutic mechanism is not clear because it takes weeks before symptoms improve and the patient feels better.

Dehydroepiandrosterone (DHEA), a neurosteroid synthesized in the nervous system from cholesterol (StoffelWagner, 2001), has been associated with antidepressive actions. Neurosteroids like other steroids, can regulate transcription via nuclear receptors, but unlike other steroids they can also rapidly influence neurons' excitability

*Correspondence: Dr G Yadid, Multidisciplinary Brain Research Center, Bar-llan University, Ramat-Gan 52900, Israel, Tel: +972 3 53। 8I23, Fax: + 9723635 4965, E-mail: yadidg@mail.biu.ac.il Received 16 May 2007; revised 26 February 2008; accepted 27 February 2008 by acting on membrane-bound, ligand-gated ion-channels (McEwen, 1991).

Elucidation of the role of neurosteroids in the pathophysiology and treatment of depression has begun recently (van Broekhoven and Verkes, 2003). Depressed patients have lower levels of plasma DHEA sulfate (DHEAS) (Barrett-Connor et al, 1999; Goodyer et al, 1998) and of saliva DHEA (Fabian et al, 2001; Takebayashi et al, 1998) than controls. Moreover, lower saliva DHEA levels in the morning correlate negatively with the severity of depression (Michael et al, 2000). In elderly remitters, DHEA and DHEAS levels decrease with time, whereas non-remitters and control subjects exhibit normal levels.

Administration of DHEA to depressed patients improves their symptoms (Wolkowitz et al, 1997, 1999), with daily treatment improving the overall well-being of the patient by preventing depressive episodes, decreasing fatigue, and increasing libido (Nadjafi-Triebsch et al, 2003). Significant improvement also occurs in men and women with midlifeonset major or minor depression upon treatment with DHEA for 6 weeks, according to the Hamilton Depression Rating Scale and the Center for Epidemiologic Studies Depression Scale ratings (Schmidt et al, 2005). Early studies showed that DHEA and DHEAS exhibit antidepressant-like 
effects in mice, as determined by the forced swim test (Prasad et al, 1997; Reddy et al, 1998).

DHEA and its sulfate derivative DHEAS, which is soluble and exhibits a greater potency, are negative allosteric modulators of the $\gamma$-aminobutyric-acid receptor $\left(\mathrm{GABA}_{\mathrm{A}} \mathrm{R}\right.$; (Demirgoren et al, 1991; Majewska et al, 1990; McEwen, 1991). However, other reports suggest that DHEAS in some systems may act opposite to DHEA (Park-Chung et al, 1999).

DHEA mechanism as antidepressant may act via modulation of the $\mathrm{GABA}_{\mathrm{A}}$ Rs activity. The GABA-ergic system can mediate depression (Lloyd et al, 1989). In depressed patients, cerebral spinal fluid levels of GABA are lower than in healthy controls (Gerner and Hare, 1981; Gold et al, 1980). Furthermore, low GABA content is correlated with depression in post-mortem temporal and frontal cortices from patients with Alzheimer's disease (Garcia-Alloza et al, 2006). In these patients, a high density of $\mathrm{GABA}_{\mathrm{A}} \mathrm{Rs}$ correlates with the severity of depression. Despite the increased cortical concentration of GABA upon antidepressant treatment of healthy individuals (Bhagwagar et al, 2004) and electroconvulsive treatment of depressed patients (Sanacora et al, 2003), antidepressants that affect GABA have yet to be developed.

$\mathrm{GABA}_{\mathrm{A}} \mathrm{Rs}$ are heterogeneous pentamers composed of various combinations of $\alpha_{1-6}, \beta_{1-4}, \gamma_{1-3}, \delta, \varepsilon, \pi$, and $\rho$ subunits. The subunit composition determines the pharmacological properties of $\mathrm{GABA}_{\mathrm{A}} \mathrm{R}$. Drugs, including neurosteroids, which interact with the receptors, can affect the subunit mRNA expression (Sun et al, 2004). $\mathrm{GABA}_{\mathrm{A}} \mathrm{R}$ usually contains two $\alpha$-subunits, two $\beta$-subunits, and either a $\gamma$ or $\delta$-subunit, with the $\delta$-subunit being rare (Sun et al, 2004). $\mathrm{GABA}_{\mathrm{A}}$ Rs containing a $\delta$-subunit, rather than a $\gamma$-subunit, are more sensitive to neurosteroids (Belelli et al, 2002), and mice lacking $\mathrm{GABA}_{\mathrm{A}} \delta$-subunits are less sensitive to neurosteroids (Brown et al, 2002; Mihalek et al, 1999, 2001; Stell et al, 2003; Wohlfarth et al, 2002). This may account for the abnormal behavior of patients with 1q36 deletion, which includes the human $\mathrm{GABA}_{\mathrm{A}} \delta$-subunit gene (Windpassinger et al, 2002).

Another site for DHEA, as an antidepressant, is sigma-1 receptors ( $\sigma 1 \mathrm{Rs})$, which are unique transmitter receptors in the central system. $\sigma 1 \mathrm{R}$ ligands exert potent neuromodulation on excitatory neurotransmitter systems, such as the glutamate and dopamine systems, which are both involved in behavioral despair (Belozertseva et al, 2007; Gershon et al, 2007). Selective $\sigma 1 \mathrm{R}$ agonists cause antidepressant-like effects on rats in swim tests (Gudelsky, 1995; Urani et al, 2001), noting that DHEA and DHEAS are also potent $\sigma 1 \mathrm{R}$ agonists (Urani et al, 2001).

Flinders sensitive line (FSL) rats are an established genetic animal model of depression with high face, construct, and predictive validities. These rats exhibit behavioral features characteristic of depression in association with changes in the mesolimbic dopaminergic and serotonergic systems. Chronic, but not acute, treatment of the FSL rats with various antidepressants abrogates their behavioral manifestations of depression (for review, see (Overstreet et al, 2005; Yadid et al, 2000).

\section{MATERIALS AND METHODS}

In the present study, we used combined methods to elucidate the mechanism of action of DHEA as an antidepressant. Using FSL rats, we initially examined whether clinically observed correlation between depression and DHEA also occurs in a rat model for depressivelike behavior. Our premise was that finding such correlation in FSL rats would facilitate determination of the antidepressive efficiency of DHEA by its external application. Then, to suggest a mechanism of action for DHEA, as a putative anti-depressant agent, we first measured transcript levels of the $\sigma 1 \mathrm{Rs}$ and $\mathrm{GABA}_{\mathrm{A}} \delta$-subunit in brains of naive FSL and SD rats. Subsequently, we pharmacologically manipulated with receptor activation and measured behavior manifestation. Finally, we located its effect by perfusing DHEAS directly into selected brain sites (VTA and NAc) using mini-pumps and monitoring its longitudinal effect on behavior.

\section{Animals}

Male FSL and Sprague-Dawley (SD) rats (230-260 g) were housed two per cage under SPF conditions of constant temperature $\left(22^{\circ} \mathrm{C}\right)$ and humidity $(50 \%)$, with a $12: 12 \mathrm{~h}$ dark/light cycle. Food and water were provided ad libitum. All animal procedures were approved by the Animal Care Committee of Bar-Ilan University and were carried out in accordance with the NIH Guide for the Care and Use of Laboratory Animals.

\section{Pharmaceutical Agents}

DHEA (Research Biochemicals International; RBI, 1 Strathmore Road, Natick, MA 01760 USA) was dissolved in $0.2 \mathrm{ml}$ DMSO and then diluted in saline (Khisti et al, 2000). DHEA was injected $(0.5,1$, or $2 \mathrm{mg} / \mathrm{kg}$ for 14 days, i.p.) with or without the GABAA agonist muscimol $(0.5 \mathrm{mg} / \mathrm{kg}$ for 14 days i.p.; RBI) diluted in saline. DHEAS (Sigma-Aldrich; Rehovot, Israel) was dissolved in phosphate-buffered saline (PBS) to yield 3 and $30 \mathrm{nM}$ solutions.

\section{Chronic Perfusion of Rat Brains with DHEAS}

Anesthetized rats $(0.5 \mathrm{ml}$ ketamine and xilasine; $2: 1$ ratio) were placed in a stereotaxic apparatus, a burr hole drilled through their skull according to stereotaxic coordinates, and a $30 \mathrm{G}$ cannula was lowered into the brain area of interest: VTA $(4.8 \mathrm{~mm}$ posterior and $1 \mathrm{~mm}$ lateral to the bregma, and $8.4 \mathrm{~mm}$ ventral to the dura), NAc shell (1.6 $\mathrm{mm}$ anterior and $1 \mathrm{~mm}$ lateral to the bregma, and $7.8 \mathrm{~mm}$ ventral to the dura), Dorsal striatum $(1.2 \mathrm{~mm}$ anterior and $2.4 \mathrm{~mm}$ lateral to the bregma, and $5 \mathrm{~mm}$ ventral to the dura). An ALZET osmotic pump (Durect corporation, Cupertino, CA; filled with 3 or $30 \mathrm{nM}$ DHEAS or PBS) was connected to the cannula using a short tubule. At the conclusion of the behavioral tests, rats were anesthetized (xylazine $10 \mathrm{mg} / \mathrm{kg}$ + ketamine $100 \mathrm{mg} / \mathrm{kg} \mathrm{IP)}$ and trypan blue $(1 \mu \mathrm{l})$ was injected through the cannula into the brain. Rats were killed by decapitation and their brains were removed, fixed in formalin, and sectioned to confirm the placement of the cannula. The position of the cannula was validated by microscopy. Only data from confirmed localization of the cannula were included. 
Swim Test for Measuring the Antidepressant Effect of Neurosteroids

Rats were placed in a cylindrical tank (height of $40 \mathrm{~cm}$, diameter of $18 \mathrm{~cm})$ that contained just enough water $\left(25^{\circ} \mathrm{C}\right)$ so that the rat could not touch the bottom with its hind paws. The amount of time that each rat was immobile during a $5 \mathrm{~min}$ period was recorded. The 15 -min pretest interval used to induce immobility during the standard forced swim test was omitted, as FSL rats are already highly immobile. All tests were conducted $24 \mathrm{~h}$ after the last drug injection and $1 \mathrm{~h}$ after the start of the $12 \mathrm{~h}$ dark period (Overstreet, 1986; Overstreet et al, 1988, 1992, 1994).

\section{Extraction of Brain Tissue and DHEA Radioimmunoassay}

After decapitation, brains of naive rats were removed and cut into $1 \mathrm{~mm}$ slices using a rat brain mold on ice. Brain regions were identified in slices by anatomical markers, and micropunches $(0.5 \mu \mathrm{m})$ were taken and frozen in $-70^{\circ} \mathrm{C}$ until extracted. Brain punches were extracted in absolute ethanol. Aliquots $(200 \mu \mathrm{l})$ of the resulting ethanol solutions were completely evaporated and subjected to a commercially available DHEA radioimmunoassay (RIA) kit (Diagnostic Systems Laboratories, Webster, TX (Doron et al, 2006; Maayan et al, 2000). This RIA utilizes DHEA-DSL 9000 Active $^{\mathrm{TM}}$ coated tubes.

\section{Brain Levels of $\mathrm{GABA}_{\mathrm{A}} \delta$-Subunit and $\sigma 1 \mathrm{R}$ mRNA}

Total RNA was isolated from brain punches of two naive groups of rats (FSL and SD) by the single-step method. Briefly, brains were punched and cDNA was synthesized. First-strand cDNA $(2 \mu \mathrm{l})$ was added to the PCR mixture containing: $0.2 \mathrm{mM}$ dNTP mix, $1 \mathrm{mM}$ of each oligonucleotide primer, and $2.5 \mathrm{U}$ Taq DNA polymerase (Boehringer-Mannheim, Mannheim, Germany) in the buffer supplied by the enzyme manufacturer. The following primers were used in this study.

$G A B A_{A} \delta$-subunit: cDNA sequence gene bank no. M35162, $5^{\prime}$ GACTACGTGGGCTCCAACCTGGA $3^{\prime}$ and $5^{\prime}$ ACTGTGGAG GTGATGCGGATGCT3'

$\sigma 1 R$ : cDNA sequence gene bank no. AF067769, 5'-CGG GGTGTTATTCCGT- $3^{\prime}$ and $5^{\prime}$-CTCATTGCTCCCCAAG- ${ }^{\prime}$

$\beta$-actin: cDNA sequence gene bank no. NM 031144, $3^{\prime}$-GG TATGGGTCAGAAGGACTCC- $5^{\prime}$ and $5^{\prime}$-TCAGGATCTTCAT GAGGTAGTC- $3^{\prime}$.

PCR was performed using a thermal cycler (MJ Research; Watertown, MA), after optimal conditions for detection of each transcript had been evaluated. Quantification of transcript levels were measured using 'Quantity one' software (Bio-rad laboratories; Hercules, CA, USA). Transcript levels were normalized to $\beta$-actin levels of the same sample. The data are presented as the ratio between the levels in FSL and SD rats.

DHEA and mRNA levels were measured in different groups of animals.

\section{Statistical Analysis}

Brain DHEA levels were analyzed by ANOVA $2 \times 6$ (strain $\times$ region). Behavioral data were analyzed using: one-way ANOVA for DHEA dose-response, ANOVA $2 \times 2$ for treatment with DHEA/saline with/without muscimol, or two-way ANOVA (region $\times$ treatment, in intra-brain treatments). All ANOVA analyses were followed by Scheffe-paired comparison analysis and/or Simple effect analysis. MANOVA $(2 \times 3 \times 2)$ with repeated measurements (region $\times$ treatment $\times$ time) was performed to analyze the lasting effect of DHEAS.

mRNA data were analyzed using Student's $t$-test.

Data are expressed as means \pm SEM, with a probability value of $p<0.05$ being considered significant.

\section{RESULTS}

\section{DHEA Levels in Rat Brains}

We tested DHEA levels in different brain regions (amygdala, CA1 of the hippocampus, hypothalamus, NAc, Prefrontalcortex, and VTA) of FSL and SD rats. ANOVA $2 \times 6$ (strain $\times$ region) revealed significant differences between strains $\left(\mathrm{F}(1,38)=17.36, p<0.01, \mathrm{Eta}^{2}=0.31\right)$ and regions $\left(\mathrm{F}(5,38)=21.64, p<0.001, \mathrm{Eta}^{2}=0.74\right)$. The mean of DHEA levels across all brain regions assessed in naive FSL rats were lower $(M=689 \mathrm{pmol} / \mu \mathrm{g}$ protein, $\mathrm{SD}=65)$ than those measured in SD rats $(M=1074 \mathrm{pmol} / \mu \mathrm{g}$ protein, $\mathrm{SD}=65)$. In addition, across strains, Scheffe analysis showed that DHEA levels in the NAc and Prefrontal-cortex were significantly lower than those in the amygdala and CA1 and that DHEA levels in the VTA were significantly lower than CA1 (Figure 1). However, no significant interaction of strain $\times$ region was found $(F(5,38)=1.17, p>0.05)$.

\section{Measuring the Antidepressive Effect of DHEA on Immobility in the Swim-test}

After finding lower levels of DHEA in limbic areas relevant to depression of FSL rats, we further tested DHEA as a possible antidepressant by adding it exogenously. The performance of FSL rats in the swim test was measured $24 \mathrm{~h}$ after the last of 14 daily i.p. injections of DHEA $(0.5,1$, or $2 \mathrm{mg} / \mathrm{kg}$ ) or saline. One-way ANOVA revealed a significant difference in immobility time between dose-

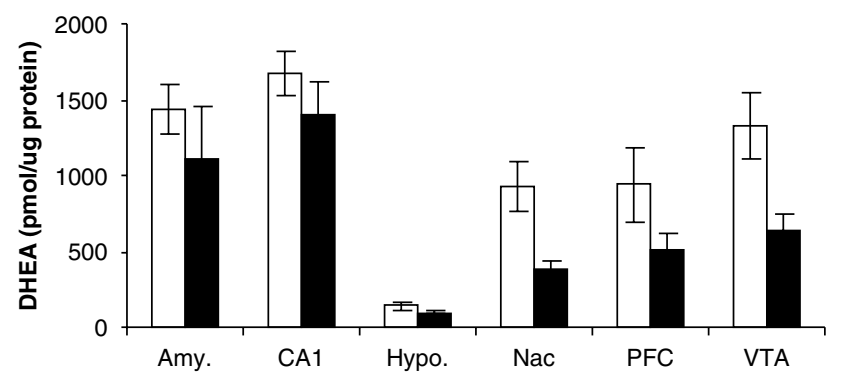

Figure I DHEA levels in brain regions of naive rats. DHEA levels were measured by radioimmunoassay in brain regions of FSL (solid column) and $\mathrm{SD}$ rats (empty column). The mean $\pm \mathrm{SEM}$ is presented. Amy-amygdala ( $n=4$ and 3 for SD and FSL respectively), CAI ( $n=4$ and 5 for SD and FSL respectively), Hypo-hypothalamus ( $n=6$ and 4 for SD and FSL respectively), Nac - nucleus accumbens ( $n=4$ and 5 for SD and FSL respectively), PFC - prefrontal cortex $(n=3)$, VTA — ventral tegmental area ( $n=4$ and 5 for SD and FSL respectively). 
groups $\left(\mathrm{F}(3,18)=5.05, p<0.01 \mathrm{Eta}^{2}=0.46\right)$. Paired comparison tests according to Scheffe revealed a significant difference between the saline treatment $(M=170 \mathrm{~s}, \mathrm{SD}=43)$ $v s$ treatment with $1 \mathrm{mg} / \mathrm{kg}$ DHEA $(M=96 \mathrm{~s}, \mathrm{SD}=24)$, but not $v s$ treatment with 0.5 or $2 \mathrm{mg} / \mathrm{kg}$ DHEA $(M=124 \mathrm{~s}$, $\mathrm{SD}=41$ and Mean $=136 \mathrm{~s}, \mathrm{SD}=15$, respectively) (Figure 2). Moreover, we found no significant effect of DHEA (1 mg/ $\mathrm{Kg} / 14$ days) on the immobility time of control SD rats (data not shown).

\section{Brain Levels of $\mathrm{GABA}_{\mathrm{A}} \delta$-Subunit and $\sigma 1 \mathrm{R}$ mRNA}

To elucidate the mechanism of action of DHEA as an antidepressant, we measured the levels of mRNA for the $\mathrm{GABA}_{\mathrm{A}} \delta$-subunit and $\sigma 1 \mathrm{R}$ in brain regions reported to play a role in depression (Overstreet et al, 2005). In the VTA of

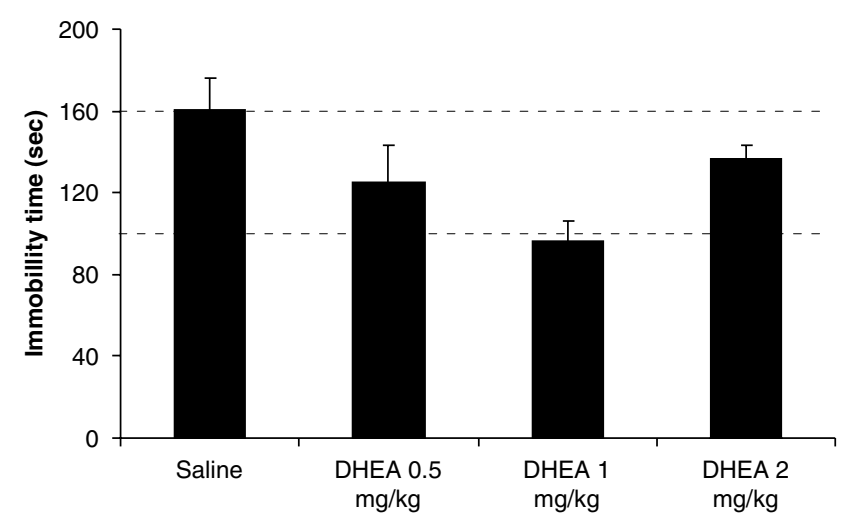

Figure 2 Performance of DHEA-treated FSL rats in the swim test. FSL rats were injected (i.p.) with DHEA (0.5, I, or $2 \mathrm{mg} / \mathrm{kg})$ or saline for 14 days and were subjected to the swim test $24 \mathrm{~h}$ after the last injection. Lower dashed line indicates the average immobility time of naive SD rats. Upper dashed line indicates the average immobility time of naive FSL rats. Mean \pm SEM of immobility time (sec) is presented. $N=7$ for saline, $n=6$ for dose of $1 \mathrm{mg} / \mathrm{kg}$ DHEA and $\mathrm{n}=5$ for doses of 0.5 and $2 \mathrm{mg} / \mathrm{kg}$ DHEA.
FSL rats, the levels of transcripts of the $\mathrm{GABA}_{\mathrm{A}} \delta$-subunit were significantly higher than in SD rats, whereas in the NAc of FSL rats they were significantly lower than in SD rats ( $T$-test, $p<0.05$, Figure 3 ). No significant changes in the transcript levels of the $\mathrm{GABA}_{\mathrm{A}} \delta$-subunit were found in the PFC, CA1, and amygdala (data not shown). Also, no significant differences were seen between the levels of $\sigma 1 \mathrm{R}$ transcripts in FSL and SD rats in all tested brain regions.

\section{GABA-Ergic Modulation of the Antidepressant Effect of DHEA}

As DHEA is a negative modulator of $\mathrm{GABA}_{\mathrm{A}} \mathrm{Rs}$, we examined whether a $\mathrm{GABA}_{\mathrm{A}}$ agonist, muscimol, can block the anti-depressant activity of DHEA. ANOVA $2 \times 2$ (DHEA $(1 \mathrm{mg} / \mathrm{kg})$ or saline $\times$ muscimol $(0,0.5 \mathrm{mg} / \mathrm{kg}))$ shows a significant effect of DHEA compared to saline $(\mathrm{F}(1,21)=$ 12.88, $p<0.01, \mathrm{Eta}^{2}=0.38$ ) and a significant interaction $\left(F(1,21)=1.21, p<0.05, \mathrm{Eta}^{2}=0.18 ;\right.$ Figure 4). Simple effect analysis to test the source of interaction revealed a significant difference in the DHEA-treated groups with/ without muscimol $\left(\mathrm{F}(1,10)=7.24, p<0.05, \mathrm{Eta}^{2}=0.42\right)$. Rats preinjected with muscimol $30 \mathrm{~min}$ before treatment with DHEA were significantly more immobile $(M=138 \mathrm{~s}$, $\mathrm{SD}=11)$ than rats treated with DHEA alone $(M=96 \mathrm{~s}$, $\mathrm{SD}=24)$. Simple effect analysis did not find a significant effect of muscimol on saline-treated rats $(M=157 \mathrm{~s}, \mathrm{SD}=8$, $M=170 \mathrm{~s}, \mathrm{SD}=43$, respectively; $\mathrm{F}(1,11)=0.44, p>0.05)$. Thus, treatment with muscimol can reverse the antidepressant action of DHEA.

\section{Effects of Intra-brain Perfusion of DHEAS on Depressive Behavior}

As we found alterations in both the levels of DHEA and $\delta$ subunit in the VTA-NAc, we assumed that the effect of exogenous DHEA on depressive behavior is mediated by these regions. FSL rats were perfused with a soluble derivate
VTA

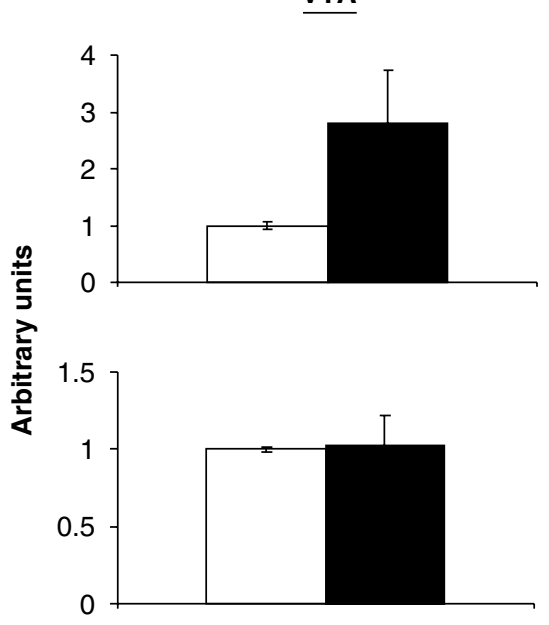

N.Ac

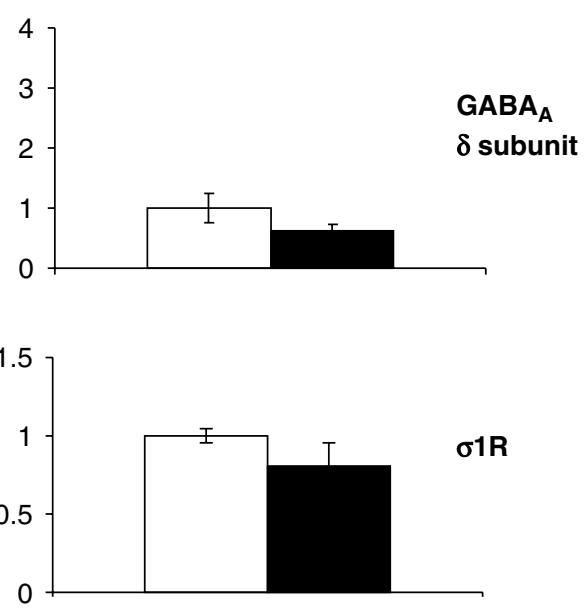

Figure 3 Levels of mRNA transcripts for GABA $\delta$-subunit and $\sigma \mid R$ in the VTA and NAc regions of FSL and SD rat brains. Transcript levels are presented as arbitrary units (GABA ${ }_{A} \delta$-subunit/ $\beta$ actin normalized to SD, and $\sigma \mid \mathrm{R} / \beta$ actin normalized to SD). FSL rats (solid columns), SD rats (empty columns). The mean \pm SEM is presented. GABA $\delta$-subunit, $n=6$, except for the VTA region of FSL rats $(n=4) ; \sigma \mid R, n=5$ for VTA and $n=7$ for NAc. 


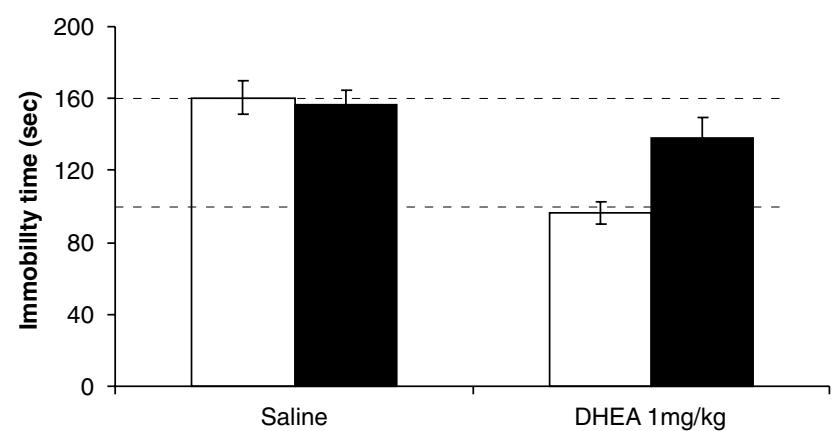

Figure 4 Immobility of saline, DHEA, and muscimol-treated FSL rats in the swim test. FSL rats were injected daily (i.p.) with saline or DHEA $(\mathrm{I} \mathrm{mg} / \mathrm{kg}$ ) with (black columns) or without muscimol $(0.5 \mathrm{mg} / \mathrm{kg}$, white columns) for 14 days. After which they were subjected to swim tests. Note: the data for $1 \mathrm{mg} / \mathrm{kg}$ DHEA treated animals is the same presented in Figure 2. Mean \pm SEM of immobility time (sec) is presented. $N=7$ for treatment with saline without muscimol and $n=6$ for all other groups. Lower dashed line indicates the average immobility time of naive SD rats. Upper dashed line indicates the average immobility time of naive FSL rats.

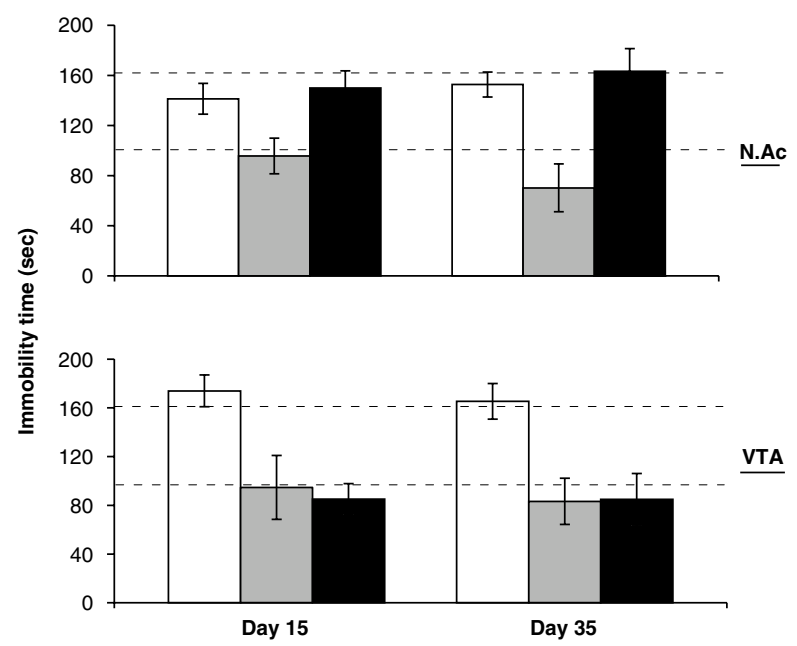

Figure 5 Immobility in swim tests of FSL rats after direct application of DHEAS into the VTA or NAc. FSL rats were perfused with DHEAS ( $3 \mathrm{nM}$ (gray columns); $30 \mathrm{nM}$ (black columns)) or PBS (white columns) directly into their VTA or NAc for 14 days. One day (day 15 of the experiment) and 21 days (day 35 of experiment) after the completion of the treatment rats were subjected to swim tests. Lower dashed line indicates the average immobility time of naive SD rats. Upper dashed line indicates the average immobility time of naive FSL rats. Mean \pm SEM of immobility time is presented. Day 15: PBS, VTA $(n=7)$, NAc $(n=6) ; 3$ nM DHEAS, VTA $(n=6)$, NAc $(n=6) ; 30 \mathrm{nM}$ DHEA, VTA $(n=7), \operatorname{NAc}(n=6)$. Day 35: PBS, VTA $(n=5)$, NAc $(n=6) ; 3$ nM DHEAS, VTA $(n=5)$, NAc $(n=4)$; 30 nM DHEA, VTA $(n=4)$, NAc $(n=5)$.

of DHEA (DHEAS, 3 or $30 \mathrm{nM}$ ) or vehicle (PBS) into the VTA and NAc.

The immobility time during the swim test $24 \mathrm{~h}$ after the completion of 14 days, treatment is presented in Figure 5. ANOVA $2 \times 3$ (region $\times$ treatment) revealed a significant difference $\left(\mathrm{F}(2,32)=11.04, p<0.01, \mathrm{Eta}^{2}=0.41\right)$ between the three treatments ( 3 or $30 \mathrm{nM}$ DHEA, or PBS) and a significant interaction (region $\times$ treatment; $\mathrm{F}(2,32)=6.93$, $\left.p<0.01, \mathrm{Eta}^{2}=0.3\right)$.
A Simple effect analysis indicated a significant difference between regions according to dose. Whereas both doses of DHEAS in the VTA significantly $(\mathrm{F}(2,17)=13.74, p<0.01$, $\left.\mathrm{Eta}^{2}=0.62\right)$ lowered immobility time $((M=95 \mathrm{~s}, \mathrm{SD}=26$ for $3 \mathrm{nM}$ and $M=85 \mathrm{~s}, \mathrm{SD}=13$ for $30 \mathrm{nM}$; compared to treatment with PBS $(M=174 \mathrm{~s}, \mathrm{SD}=13))$, in the NAc, only treatment with $3 \mathrm{nM}$ DHEAS significantly $(\mathrm{F}(2,15)=4.71$, $\left.p<0.05, \quad \mathrm{Eta}^{2}=0.39\right) \quad$ affected the rat's performance $((M=96 \mathrm{~s}, \mathrm{SD}=14)$ compared to PBS $(M=141 \mathrm{~s}, \mathrm{SD}=12))$.

We also tested the long-term effect of DHEAS treatment on immobility of FSL rats. The same rats (treated with PBS or DHEAS ( 3 or $30 \mathrm{nM}$ )) were again given the swim test 21 days after the cessation of treatment (day 35 of experiment). MANOVA $2 \times 3 \times 2$ (region $\times$ treatment $\times$ time) with repeated measures have not found a significant difference according to time $(\mathrm{F}(1,23)=1.52, p>0.05)$. Moreover, we did not find significant interactions of time with area and/or treatment. Thus, the significant effect of intra-brain DHEAS continues for at least 21 days after completion of treatment.

We further tested the brain region's specificity of the DHEAS treatment. We perfused DHEAS or a vehicle (PBS) into the dorsal striatum of FSL rats, an area outside the mesolimbic pathway. We used $3 \mathrm{nM}$ DHEAS, the dose that had a beneficial effect when applied both into the VTA and NAc. After 14 days of treatment, the rat's performance in the swim test was monitored and compared to the above mentioned treatments in both the NAc and VTA. ANOVA $3 \times 2$ (region (NAc, VTA, dorsal striatum) $\times$ treatment (DHEA, PBS)) revealed significant differences according to treatment $\left(\mathrm{F}(1,27)=8.78, \quad p<0.01, \quad \mathrm{Eta}^{2}=0.25\right)$ and a significant region $\times$ treatment interaction $(\mathrm{F}(2,27)=4.89$, $\left.p<0.05, \mathrm{Eta}^{2}=0.27\right)$. Simple effect analysis did not find any significance between the different treatments in the dorsal striatum $(M=136 \mathrm{~s}, \mathrm{SD}=15$ for $\mathrm{PBS}$ or $\mathrm{M}=152 \mathrm{~s}, \mathrm{SD}=21$ DHEAS $3 \mathrm{nM} ; \mathrm{F}(1,6)=0.44, p>0.05)$. Thus, DHEAS has no antidepressive effect when applied outside the NAc-VTA circuit.

\section{DISCUSSION}

Although the usefulness of DHEA as an antidepressant has been suggested (Dubrovsky, 2005; Wolf and Kirschbaum, 1999; Wolkowitz et al, 1999), its mechanism of action and role in depression is poorly understood. Herein, we used an animal model of depression (FSL rats) to demonstrate alterations in DHEA levels in some brain regions relevant to depression. This is the first time that decreases in DHEA levels have been shown in brain regions central to manifestation of depressive behavior in an animal model (Figure 1). Furthermore, chronic treatment of FSL rats with DHEA significantly decreased their immobility in the swim test (Figure 2) to the same extent as conservative antidepressants (Dremencov et al, 2004), thus confirming an antidepressive-like action of DHEA in an animal model of depression. The dose response curve of DHEA is concordant with other reports (Urani et al, 2001) demonstrating a narrow therapeutic window.

DHEA may act through the neurotransmitter receptors $\mathrm{GABA}_{\mathrm{A}} \mathrm{R}, \sigma 1 \mathrm{R}$ and NMDAR (Majewska et al, 1990; Monnet et al, 1995; Urani et al, 2001). A role in depression for $\sigma 1 \mathrm{R}$ 
and $\mathrm{GABA}_{\mathrm{A}} \mathrm{R}$ has already been suggested (Gudelsky, 1995; Lloyd et al, 1989; Urani et al, 2001). Here (Figure 3) we demonstrate that FSL rats do not express differences in the levels of $\sigma 1 \mathrm{R}$ mRNA, but that they do so in those of $\delta$-subunit of the $\mathrm{GABA}_{\mathrm{A}} \mathrm{R}$ (compared to SD rats) in the VTA-NAc (Figure 3). These mesolimbic regions were suggested to have a central role in depressive behavior (Overstreet et al, 2005). Incorporation of the $\delta$-subunit dramatically augments the GABA-enhancing actions of the steroid (Belelli et al, 2002; Mihalek et al, 1999, 2001). Therefore, the elevated levels of mRNA for the $\mathrm{GABA}_{\mathrm{A}}$ $\delta$-subunit in the VTA of FSL rats might be due to an intrinsic GABA-ergic intraneuron modulation (compensation) for low levels of DHEA in this brain region (Concas et al, 1999; Gulinello et al, 2001; Holt et al, 1996; Mahmoudi et al, 1997). The contrasting lower levels of mRNA for the $\delta$-subunit in the NAc of FSL compared to SD rats can be explained by different localization of GABA modulation on ascending neurons (Akiyama et al, 2004; Bankson and Yamamoto, 2004; Tao and Auerbach, 2002; Yan et al, 2004). Our results may point to a different role for the $\mathrm{GABA}_{\mathrm{A}} \mathrm{Rs}$ in the NAc compared to the VTA, some of which may be explained by localization of the receptors pre- or post-synaptically (Ikemoto et al, 1997; Yan et al, 2004). Moreover, our results suggest that an imbalance in the mesolimbic GABA-ergic system together with the alterations in DHEA levels may lead to the pathological behavioral outcomes observed in the FSL rats.

The GABA-ergic system is an important regulator of dopaminergic neurons (Akiyama et al, 2004), which are relevant to depression (Dremencov et al, 2006; Friedman et al, 2007). Specifically, $\mathrm{GABA}_{\mathrm{A}} \mathrm{Rs}$ within the VTA regulate dopamine output to the NAc (Bankson and Yamamoto, 2004; Yan et al, 2004), suggesting a modulatory role for these receptors in depression (Garcia-Alloza et al, 2006). Furthermore, co-administration of a $\mathrm{GABA}_{\mathrm{A}}$ agonist (muscimol) and DHEA blocked the beneficial effect of DHEA on depressive behavior (Figure 4), confirming that the $\mathrm{GABA}_{\mathrm{A}} \mathrm{R}$ is the main target for DHEA in depression. Hence, elevating mesolimbic DHEA levels exogenously may overcome lower endogenic DHEA levels by activating the GABAergic system and correcting depressive-like behavior. It is important to note that DHEA is a negative modulator of the $\mathrm{GABA}_{\mathrm{A}} \mathrm{R}$. Unlike full antagonists, such as bicuculline, which may trigger seizures, it does not have aversive side effects. This may explain the nonavailability of full $\mathrm{GABA}_{\mathrm{A}} \mathrm{R}$ antagonists as antidepressants. For the same reason, we avoided manipulating with $\mathrm{GABA}_{\mathrm{A}} \mathrm{R}$ antagonists to augment DHEA antidepressive effects. Although we found a central role for $\mathrm{GABA}_{\mathrm{A}} \mathrm{R}$ in the antidepressive mechanism of DHEA, but did not find differences in $\sigma 1 \mathrm{R}$ transcript levels in FSL compared to SD rats, we do not rule out the possibility that other receptors such as $\sigma 1$ Rs and NMDARs may also be involved in DHEA antidepressive effects.

The content of monoamines in the limbic regions of FSL rats is not affected by repeated exogenously applied DHEA (unpublished findings, R Genud and G Yadid) in contrast to treatment with conservative anti-depressants (Overstreet et al, 2005; Zangen et al, 1997), which further suggests that DHEA may affect depressive behavior differently than the established mechanism for antidepressants (Shapira et al, 1994).
To locate the DHEA site of action in the brain, we treated FSL rats with DHEAS directly into the brain. DHEAS is more soluble in water than DHEA, is converted to DHEA in the cerebral tissue (Kroboth et al, 1999), and is reported to affect the brain neurotransmitter receptors $\left(\mathrm{GABA}_{\mathrm{A}} \mathrm{R}\right.$, NMDAR, $\sigma 1 \mathrm{R}$ ) in the same mode as DHEA (Majewska, 1992; Monnet et al, 1995; Urani et al, 2001). Therefore, DHEAS was used for the direct intrabrain administration. In FSL rats, perfusion of DHEAS directly into the VTA and $\mathrm{Nac}$, but not into the dorsal striatum, caused the same effects on depressive behavior as i.p. injection of DHEA (Figure 5). These results suggest that the antidepressive action of DHEAS in the brain is localized in the mesolimbic system. In the NAc, the sensitivity of $\mathrm{GABA}_{\mathrm{A}} \mathrm{R}$ to DHEAS might be higher, because as the concentration of DHEAS increased, its effect on depressive behavior decreased. This sensitivity can be explained by our neurochemical findings indicating lower DHEA levels in the NAc compared to the VTA in both SD and FSL rats (Figure 1). Thus, $\mathrm{GABA}_{\mathrm{A}} \mathrm{Rs}$ are tonically exposed in the NAc to low concentration of local DHEA compared to the $\mathrm{GABA}_{\mathrm{A}} \mathrm{Rs}$ in the VTA. In addition, we found a decrease in the levels of the $\mathrm{GABA}_{\mathrm{A}}$ $\delta$-subunit in the Nac, whereas there is an increase in the VTA of FSL rats compared to SD rats. These lowered levels in the NAc can explain a higher sensitivity for DHEAS in the NAc compared to the VTA. Moreover, this is reminiscent of high doses of progesterone downregulating $\mathrm{GABA}_{\mathrm{A}} \mathrm{R}$ in mice (Czlonkowska et al, 2001), due to excessive stimulation of $\mathrm{GABA}_{\mathrm{A}} \mathrm{Rs}$ by progesterone metabolites (neurosteroids).

The effect of DHEAS on the behavioral manifestations of depression persisted for at least 21 days after completion of the 14-day treatment (Figure 5), indicating its long-lasting effect. This long-lasting effect of DHEAS might either be due to changes in $\mathrm{GABA}_{\mathrm{A}} \mathrm{Rs}$ density or sensitivity or to changes in the neurosteroid metabolism and synthesis in the brain.

On the basis of our results, we propose a role for the neurosteroid DHEA/DHEAS in the pathophysiology and treatment of depression. We found that DHEA/DHEAS acts as an antidepressant via the GABA-ergic mechanism, unlike the currently used antidepressants that target monoamine systems, and has a long-term effect on the mesolimbic VTA-NAc pathway, which is centrally involved in depression.

\section{ACKNOWLEDGEMENTS}

We thank Mrs A Ulmann and Dr B Schick for reviewing and editing this article, and the Ministry of Health for supporting this study. We thank Dr D Har-Even for his critical help with the statistics analyses.

\section{DISCLOSURE/CONFLICT OF INTEREST}

We declare that except for income received from my primary employer, no financial support or compensation has been received from any individual or corporate entity over the past 3 years for research or professional service and that there are no personal financial holdings that could be perceived as constituting a potential conflict of interest. 


\section{REFERENCES}

Akiyama G, Ikeda H, Matsuzaki S, Sato M, Moribe S, Koshikawa N et al (2004). GABAA and GABAB receptors in the nucleus accumbens shell differentially modulate dopamine and acetylcholine receptor-mediated turning behaviour. Neuropharmacology 46: 1082-1088.

Angst J (1992). Epidemiology of depression. Psychopharmacology (Berl ) 106(Suppl): S71-S74.

Bankson MG, Yamamoto BK (2004). Serotonin-GABA interactions modulate MDMA-induced mesolimbic dopamine release. J Neurochem 91: 852-859.

Barrett-Connor E, von Muhlen D, Laughlin GA, Kripke A (1999). Endogenous levels of dehydroepiandrosterone sulfate, but not other sex hormones, are associated with depressed mood in older women: the Rancho Bernardo Study. J Am Geriatr Soc 47: 685-691.

Belelli D, Casula A, Ling A, Lambert JJ (2002). The influence of subunit composition on the interaction of neurosteroids with GABA(A) receptors. Neuropharmacology 43: 651-661.

Belozertseva IV, Kos T, Popik P, Danysz W, Bespalov AY (2007). Antidepressant-like effects of mGluR1 and mGluR5 antagonists in the rat forced swim and the mouse tail suspension tests. Eur Neuropsychopharmacol 17: 172-179.

Bhagwagar Z, Wylezinska M, Taylor M, Jezzard P, Matthews PM, Cowen PJ (2004). Increased brain GABA concentrations following acute administration of a selective serotonin reuptake inhibitor. Am J Psychiatry 161: 368-370.

Brown N, Kerby J, Bonnert TP, Whiting PJ, Wafford KA (2002). Pharmacological characterization of a novel cell line expressing human alpha(4)beta(3)delta GABA(A) receptors. Br J Pharmacol 136: 965-974.

Concas A, Follesa P, Barbaccia ML, Purdy RH, Biggio G (1999). Physiological modulation of GABA(A) receptor plasticity by progesterone metabolites. Eur J Pharmacol 375: 225-235.

Czlonkowska AI, Krzascik P, Sienkiewicz-Jaros H, Siemiqtkowski M, Szyndler J, Maciejak P et al (2001). Rapid downregulation of GABA-A receptors after pretreatment of mice with progesterone. Pol J Pharmacol 53: 385-388.

Demirgoren S, Majewska MD, Spivak CE, London ED (1991). Receptor binding and electrophysiological effects of dehydroepiandrosterone sulfate, an antagonist of the GABAA receptor. Neuroscience 45: 127-135.

Doron R, Fridman L, Gispan-Herman I, Maayan R, Weizman A, Yadid G (2006). DHEA, a neurosteroid, decreases cocaine selfadministration and reinstatement of cocaine-seeking behavior in rats. Neuropsychopharmacology 31: 2231-2236.

Dremencov E, Gispan-Herman I, Rosenstein M, Mendelman A, Overstreet DH, Zohar J et al (2004). The serotonin-dopamine interaction is critical for fast-onset action of antidepressant treatment: in vivo studies in an animal model of depression. Prog NeuroPsychopharmacol Biol Psychiatry 28: 141-147.

Dremencov E, Weizmann Y, Kinor N, Gispan-Herman I, Yadid G (2006). Modulation of dopamine transmission by 5HT2C and 5HT3 receptors: a role in the antidepressant response. Curr Drug Targets 7: 165-175.

Dubrovsky BO (2005). Steroids, neuroactive steroids and neurosteroids in psychopathology. Prog Neuropsychopharmacol Biol Psychiatry 29: 169-192.

Fabian TJ, Dew MA, Pollock BG, Reynolds III CF, Mulsant BH, Butters MA et al (2001). Endogenous concentrations of DHEA and DHEA-S decrease with remission of depression in older adults. Biol Psychiatry 50: 767-774.

Friedman A, Deri I, Friedman Y, Dremencov E, Goutkin S, Kravchinsky E et al (2007). Decoding of dopaminergic mesolimbic activity and depressive behavior. J Molec Neurosci 32: $72-79$.
Garcia-Alloza M, Tsang SW, Gil-Bea FJ, Francis PT, Lai MK, Marcos B et al (2006). Involvement of the GABAergic system in depressive symptoms of Alzheimer's disease. Neurobiol Aging 27: $1110-1117$.

Gerner RH, Hare TA (1981). CSF GABA in normal subjects and patients with depression, schizophrenia, mania, and anorexia nervosa. Am J Psychiatry 138: 1098-1101.

Gershon AA, Vishne T, Grunhaus L (2007). Dopamine D2-like receptors and the antidepressant response. Biol Psychiatry 61: 145-153.

Gold BI, Bowers Jr MB, Roth RH, Sweeney DW (1980). GABA levels in CSF of patients with psychiatric disorders. Am J Psychiatry 137: 362-364.

Goodyer IM, Herbert J, Altham PM (1998). Adrenal steroid secretion and major depression in 8- to 16-year-olds, III. Influence of cortisol/DHEA ratio at presentation on subsequent rates of disappointing life events and persistent major depression. Psychol Med 28: 265-273.

Gudelsky GA (1995). Effects of sigma receptor ligands on the extracellular concentration of dopamine in the striatum and prefrontal cortex of the rat. Eur J Pharmacol 286: 223-228.

Gulinello M, Gong QH, Li X, Smith SS (2001). Short-term exposure to a neuroactive steroid increases alpha4 GABA(A) receptor subunit levels in association with increased anxiety in the female rat. Brain Res 910: 55-66.

Holt RA, Bateson AN, Martin IL (1996). Chronic treatment with diazepam or abecarnil differently affects the expression of GABAA receptor subunit mRNAs in the rat cortex. Neuropharmacology 35: 1457-1463.

Ikemoto S, Kohl RR, McBride WJ (1997). GABA(A) receptor blockade in the anterior ventral tegmental area increases extracellular levels of dopamine in the nucleus accumbens of rats. J Neurochem 69: 137-143.

Khisti RT, Chopde CT, Jain SP (2000). Antidepressant-like effect of the neurosteroid 3alpha-hydroxy-5alpha-pregnan-20-one in mice forced swim test. Pharmacol Biochem Behav 67: 137-143.

Kroboth PD, Salek FS, Pittenger AL, Fabian TJ, Frye RF (1999). DHEA and DHEA-S: a review. J Clin Pharmacol 39: 327-348.

Lloyd KG, Zivkovic B, Scatton B, Morselli PL, Bartholini G (1989). The gabaergic hypothesis of depression. Prog Neuropsychopharmacol Biol Psychiatry 13: 341-351.

Maayan R, Yagorowski Y, Grupper D, Weiss M, Shtaif B, Kaoud MA et al (2000). Basal plasma dehydroepiandrosterone sulfate level: a possible predictor for response to electroconvulsive therapy in depressed psychotic inpatients. Biol Psychiatry 48: 693-701.

Mahmoudi M, Kang MH, Tillakaratne N, Tobin AJ, Olsen RW (1997). Chronic intermittent ethanol treatment in rats increases GABA(A) receptor alpha4-subunit expression: possible relevance to alcohol dependence. J Neurochem 68: 2485-2492.

Majewska MD (1992). Neurosteroids: endogenous bimodal modulators of the GABAA receptor. Mechanism of action and physiological significance. Prog Neurobiol 38: 379-395.

Majewska MD, Demirgoren S, Spivak CE, London ED (1990). The neurosteroid dehydroepiandrosterone sulfate is an allosteric antagonist of the GABAA receptor. Brain Res 526: 143-146.

McEwen BS (1991). Non-genomic and genomic effects of steroids on neural activity. Trends Pharmacol Sci 12: 141-147.

Michael A, Jenaway A, Paykel ES, Herbert J (2000). Altered salivary dehydroepiandrosterone levels in major depression in adults. Biol Psychiatry 48: 989-995.

Mihalek RM, Banerjee PK, Korpi ER, Quinlan JJ, Firestone LL, Mi $\mathrm{ZP}$ et al (1999). Attenuated sensitivity to neuroactive steroids in gamma-aminobutyrate type A receptor delta subunit knockout mice. Proc Natl Acad Sci USA 96: 12905-12910.

Mihalek RM, Bowers BJ, Wehner JM, Kralic JE, VanDoren MJ, Morrow AL et al (2001). GABA(A)-receptor delta subunit 
knockout mice have multiple defects in behavioral responses to ethanol. Alcohol Clin Exp Res 25: 1708-1718.

Monnet FP, Mahe V, Robel P, Baulieu EE (1995). Neurosteroids, via sigma receptors, modulate the $\left[{ }^{3} \mathrm{H}\right]$ norepinephrine release evoked by N-methyl-D-aspartate in the rat hippocampus. Proc Natl Acad Sci USA 92: 3774-3778.

Nadjafi-Triebsch C, Huell M, Burki D, Rohr UD (2003). Progesterone increase under DHEA-substitution in males. Maturitas 45: 231-235.

Overstreet DH (1986). Selective breeding for increased cholinergic function: development of a new animal model of depression. Biol Psychiatry 21: 49-58.

Overstreet DH, Friedman E, Mathe AA, Yadid G (2005). The Flinders Sensitive Line rat: a selectively bred putative animal model of depression. Neurosci Biobehav Rev 29: 739-759.

Overstreet DH, Janowsky DS, Pucilowski O, Rezvani AH (1994). Swim test immobility co-segregates with serotonergic but not cholinergic sensitivity in cross-breeds of Flinders Line rats. Psychiatr Genet 4: 101-107.

Overstreet DH, Rezvani AH, Janowsky DS (1992). Genetic animal models of depression and ethanol preference provide support for cholinergic and serotonergic involvement in depression and alcoholism. Biol Psychiatry 31: 919-936.

Overstreet DH, Russell RW, Crocker AD, Gillin JC, Janowsky DS (1988). Genetic and pharmacological models of cholinergic supersensitivity and affective disorders. Experientia 44: 465-472.

Park-Chung M, Malayev A, Purdy RH, Gibbs TT, Farb DH (1999). Sulfated and unsulfated steroids modulate gamma-aminobutyric acidA receptor function through distinct sites. Brain Res 830: 72-87.

Prasad A, Imamura M, Prasad C (1997). Dehydroepiandrosterone decreases behavioral despair in high- but not low-anxiety rats. Physiol Behav 62: 1053-1057.

Reddy DS, Kaur G, Kulkarni SK (1998). Sigma (sigma1) receptor mediated anti-depressant-like effects of neurosteroids in the Porsolt forced swim test. Neuroreport 9: 3069-3073.

Sanacora G, Mason GF, Rothman DL, Hyder F, Ciarcia JJ, Ostroff $\mathrm{RB}$ et al (2003). Increased cortical GABA concentrations in depressed patients receiving ECT. Am J Psychiatry 160: 577-579.

Schmidt PJ, Daly RC, Bloch M, Smith MJ, Danaceau MA, St Clair LS et al (2005). Dehydroepiandrosterone monotherapy in midlife-onset major and minor depression. Arch Gen Psychiatry 62: $154-162$.

Shapira B, Newman M, Lerer B (1994). Serotonergic mechanisms in depression: clinical insights and biological correlates. Isr J Med Sci 30: 162-167.

Stell BM, Brickley SG, Tang CY, Farrant M, Mody I (2003). Neuroactive steroids reduce neuronal excitability by selectively enhancing tonic inhibition mediated by delta subunit-containing GABAA receptors. Proc Natl Acad Sci USA 100: 14439-14444.
Stoffel-Wagner B (2001). Neurosteroid metabolism in the human brain. Eur J Endocrinol 145: 669-679.

Sun C, Sieghart W, Kapur J (2004). Distribution of alpha1, alpha4, gamma2, and delta subunits of GABAA receptors in hippocampal granule cells. Brain Res 1029: 207-216.

Takebayashi M, Kagaya A, Uchitomi Y, Kugaya A, Muraoka M, Yokota $\mathrm{N}$ et al (1998). Plasma dehydroepiandrosterone sulfate in unipolar major depression. Short communication. J Neural Transm 105: 537-542.

Tao R, Auerbach SB (2002). GABAergic and glutamatergic afferents in the dorsal raphe nucleus mediate morphine-induced increases in serotonin efflux in the rat central nervous system. J Pharmacol Exp Ther 303: 704-710.

Urani A, Roman FJ, Phan VL, Su TP, Maurice T (2001). The antidepressant-like effect induced by sigma(1)-receptor agonists and neuroactive steroids in mice submitted to the forced swimming test. J Pharmacol Exp Ther 298: 1269-1279.

van Broekhoven F, Verkes RJ (2003). Neurosteroids in depression: a review. Psychopharmacology (Berl) 165: 97-110.

Windpassinger C, Kroisel PM, Wagner K, Petek E (2002). The human gamma-aminobutyric acid A receptor delta (GABRD) gene: molecular characterisation and tissue-specific expression. Gene 292: 25-31.

Wohlfarth KM, Bianchi MT, Macdonald RL (2002). Enhanced neurosteroid potentiation of ternary $\mathrm{GABA}(\mathrm{A})$ receptors containing the delta subunit. J Neurosci 22: 1541-1549.

Wolf OT, Kirschbaum C (1999). Dehydroepiandrosterone replacement in elderly individuals: still waiting for the proof of beneficial effects on mood or memory. J Endocrinol Invest 22: 316 .

Wolkowitz OM, Reus VI, Keebler A, Nelson N, Friedland M, Brizendine L et al (1999). Double-blind treatment of major depression with dehydroepiandrosterone. Am J Psychiatry 156: 646-649.

Wolkowitz OM, Reus VI, Roberts E, Manfredi F, Chan T, Raum WJ et al (1997). Dehydroepiandrosterone (DHEA) treatment of depression. Biol Psychiatry 41: 311-318.

Yadid G, Nakash R, Deri I, Tamer G, Kinor N, Gispan I et al (2000). Elucidation of the neurobiology of depression: insights from a novel genetic animal model. Prog Neurobiol 62: 353-378.

Yan QS, Zheng SZ, Yan SE (2004). Involvement of 5-HT1B receptors within the ventral tegmental area in regulation of mesolimbic dopaminergic neuronal activity via GABA mechanisms: a study with dual-probe microdialysis. Brain Res 1021: 82-91.

Zangen A, Overstreet DH, Yadid G (1997). High serotonin and 5-hydroxyindoleacetic acid levels in limbic brain regions in a rat model of depression: normalization by chronic antidepressant treatment. J Neurochem 69: 2477-2483. 